such as electrical circuits, but does it exist in relation to the fundamental processes of embryonic development, such as gene activation, protein synthesis and the like? If it does, I do not think that any cybernetician has yet expressed it in a way that makes its relevance to embryology clear. Certainly Apter does not do so. His book is a summary of beginnings which always seem to be promising to lead to something important but have, as yet, scarcely done so. C. H. WADDINGTON

\section{TREES IN BORNEO}

Manual of the Dipterocarp Trees of Brunei State By P. S. Ashton. Pp. xii $+242+58$ plates. (London: Oxford University Press, 1964.) 63s. net.

ONE of the major economic products of Borneo is timber, and this is largely produced by trees belonging to the family Dipterocarpaceae. It is therefore of considerable importance that this group should be well studied taxonomically. Many of the trees concerned are forest giants some $150-200 \mathrm{ft}$. high, so any taxonomic work based solely on herbarium specimens (often accompanied by inadequate field-notes) is obviously likely to be unsatisfactory. This applies especially to the Dipterocarpaceae, where considerable variation occurs between the vegetative characters of juvenile and mature leaves, and consequently a lack of suitable field-experience has led to misinterpretations of the differences between herbarium specimens, thus leading to wrong taxonomic decisions. The ideal circumstances for a taxonomist working on this group is for him to have first-hand knowledge of all the species in the field. This ideal has been achieved by Dr. Ashton in his investigations of the Dipterocarpaceae of Brunei. The major geographical centre of this family is Borneo, where more than half the species occur. Therefore, in spite of the small size of the State of Brunei the number of species which occur there is more than 150, which is just about the number of those which occur in the much larger area of Malaya. Nine genera are represented in Brunei, the largest being Shorea with 75 species; Dipterocarpus, Hopea and Vatica each have 20 or more species. Dr. Ashton was able to examine a total of some 1,500 Dipterocarp' collections from Brunei, nearly half of which he collected himself. All this, in addition to his thorough knowledge of the trees themselves and their ecology, has provided the secure foundation of this excellent book. Its main purpose, as stated by the author, is to provide foresters with a work which will enable them to recognize all the species in the field, thus leading to a stable vernacular and trade terminology. This manual, furthermore, is intended as a basis for a complete revision of Bornean Dipterocarps.

Field-keys and systematic keys are provided both to the genera or main field-groups and to the species. The systematic keys include flower and fruit characters. As Symington's Foresters Manual of Dipterocarps is still widely used in Brunei and comprehensive generic deseriptions were provided in it, these have not been repeated in this new publication, but full diagnostic characters of the genera are provided. The treatment of each species gives the synonymy, vernacular names, separate field and herbarium descriptions as well as notes on uses, distribution and regeneration. Herbarium specimens are also cited. The herbarium descriptions are very full and give much useful detail including seedling and sapling characters. Many of the species are illustrated by line-drawings of the leaves and fruits; there are also many photographs of trees, showing especially the appearance of their bark. In view of the number and diversity of species of Shorea involved, this genus receives a somewhat different treatment. Nine sections are recognized and some of these are further subdivided. The systematic key includes all the species occurring in Brunei. The treatment of the species is divided up into the four field-groups, each provided with a separate field-key; the species in each field-group are numbered separately, which is a disadvantage to the taxonomist, who will want to use this book as well as the forester. (The species in the complete systematic key are unnumbered.) It is noteworthy that although $S$. albida belongs to section Anthoshorea, which constitutes the White Meranti field-group, on gross field-eharacters it is a Red Meranti. A similar situation occurs in Hopea, where. there are both four botanical groups and four field-groups, but these do not entirely correspond with one another.

Although intended primarily for foresters, the keys and detailed descriptions will also make this work most useful to taxonomists. This important book, which has been printed in Singapore, has been attractively and well produced.

L. L. FORMAN

\section{GRASSHOPPERS IN RUSSIA}

\section{Locusts and Grasshoppers (Catantopinae)}

By L. L. Mishchenko. (Fauna of the U.S.S.R.: Orthoptera, Vol. 4, No. 2.) Translated from the Russian by B. Munitz. Pp. xiii +560. (Jerusalem: Israel Program for Scientific Translations; London: Oldbourne Press, 1965.) $135 s$.

A TAXONOMiC work published in 1952 and translated 14 years later cannot be expected to provide up-to-date information on the fauna of large parts of two continents, but its English version will be welcomed by specialists in this group of insects. They should, however, bear in mind the somewhat vague definition of the area covered, the author merely saying that he disregarded "species inhabiting western Europe, the Mediterranean region, southern Iran, Afghanistan, India, China and Japan, which are not found in U.S.S.R.". These limitations, moreover, are applied inconsistently, since the book includes the Mediterranean Tropidopola longicornis, Pezotettix anatolica, Sphenophyma rugulosa (and even a new subspecies of Miramella from Albania), Tibetan genera Indopodisma and Kingdonella, Indian Pachyacris and Patanga, some species from southern Iran and Fruhstoferiola of south-east China. This would be less objectionable, were it not that other genera and species from the same areas are omitted; thus, several species of Kabulia from Quetta are left out, but a Conophyma from that locality is included; two species of Dericorys from Baluchistan are in the book, but a third is not; two Iranian genera, Lyrotylus and Dabba, are mentioned in an introductory chapter, but ignored in the text.

The introductory chapters dealing with the morphology, development and ecology of Acrididae are brief. Anatomy is not even mentioned, except for a rough sketch of the male copulatory apparatus of Conophyma; this character has been used by taxonomists long before 1952, but it is ignored in keys and descriptions. A fairly long chapter deals with the geographical distribution of Catantopinae, but mainly in the form of long lists of tribes (illustrated by maps) and genera supposed to be characteristic of various regions; the fauna of the Palaearctic region and of the U.S.S.R. are dealt with in more detail, but in the same uninspired manner.

The bibliography is in two parts-papers in Russian, with their titles both transliterated and translated, and those in other languages.

The classification is still that of Brunner-Wattenwyl (1893), with a few recent modifications, but the author himself has introduced hardly any improvements. His main original contribution is a key to small apterous grasshoppers of the genus Conophyma. This is represented by sixty-eight species in the high mountains of Central Asia providing a remarkable example of speciation by isolation; most of the species have been described by 'Mishchenko' himself. They alone make up half the 